\title{
A short report on article by V. Pruliere-Escabasse et al., Vol. 27: 285-286, 2009
}

\author{
Terence M. Davidson
}

Received: 5 February 2010 / Accepted: 7 April 2010 /Published online: 4 May 2010

(C) The Author(s) 2010. This article is published with open access at Springerlink.com

February 01, 2010

Investigational New Drugs

The Journal of New Anticancer Agents

Editor-in-Chief, Eric K. Rowinsky

Attn: Laura.Walsh laura.walsh@springer.com

Ann Salvador anna.salvador@springer.com

Re: A short report on article by V. Pruliere-Escabasse et al., Vol. 27: 285-286, 2009

\section{Dear Editor,}

I have recently read the article on "Rhinitis and epistaxis in patients treated with antiangiogenic therapy." I take exception to their conclusion. I have used bevacizumab, a VEGF inhibitor successfully in patients with HHT epistaxis. In the first report [1] the bevacizumab was injected and in the second report [2] the bevacizumab was sprayed. In both applications the bevacizumab was used in low concentrations namely $50-100 \mathrm{mgs}$ and not in cancer doses such as 510 mgs per kilograms IV q 2 weeks.

In both papers we report resolution of HHT related epistaxis. In no cases did we see crusting or atrophic rhinitis. I strongly suspect that whatever nasal changes were seen, may or may not be related to the patient's disease or the therapy, but if indeed it was, I would be more suspect about the combination chemotherapy then I would about the VEGF inhibitors. As VEGF inhibitors play an important role in the treatment of a number of nasal conditions, this report of an adverse event must be taken with great caution.

Sincerely,

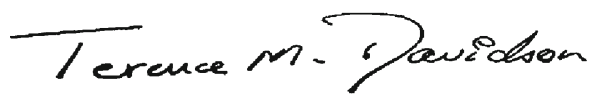

Terence M. Davidson, M.D., FACS

Professor of Surgery

Division of Otolaryngology-Head and Neck Surgery

Associate Dean for UCSD Continuing Medical Education

Section Chief, VA Head and Neck Surgery

TMD:bas

References:

[1]. Simonds J, Miller F, Mandel J, and Davidson TM. The Effect of Bevacizumab (Avastin) Treatment on Epistaxis in Hereditary Hemorrhagic Telangiectasia (HHT). Laryngoscope 119:988-992, 2009.

[2]. Davidson TM, Olitsky SE, Wei JL. Hereditary Hemorrhagic Telangiectasia/Avastin. Laryngoscope 120:432-435, 2010. (pending: vol, issue and pages.)

T. M. Davidson $(\bowtie)$

USCD Medical Center,

San Diego, CA, USA

e-mail: tdavidson@ucsd.edu 
Christophe Massard, MD

Department of Medecine Institut Gustave Roussy

39 rue C. Desmoulins

Villejuif, France

Phone: 33-142114317

Fax: 33-142115211

E-mail: christophe.massard@igr.fr

March 25th, 2010

\section{Investigational New Drugs}

\section{Dear Editor}

We thank Dr Terence M Davidson for his interest concerning our recent letter published in Investigational new drugs which reported " atrophic rhinitis » in patients treated with antiangiogenic therapies.

Dr Terence Davidson reported in the correspondance that patients with HHT treated with local or systemic low dose of bevaczumab do not present any " atrophic rhinitis ».
First of all, our patients were treated with standard dose of antiangiogenic therapies (VEGFR inhibitors or VEGF inhibitors). Secondly, all our patients were treated with systemic therapies and not with local application. Finally, 2 patients were only treated with VEGFR inhibitor (without any chemotherapy) and also presented the same « atrophic rhinitis $»$.

We think that this observation is very interesting, but our experience (with more than 30 patients prospectively followed-up)clearly shows that patients treated with anticancer doses of VEGFR or VEGF inhibitors usually develop very particular rhinitis.

Christophe Massard, Virginie Escabasse, Jean-Charles Soria

Open Access This article is distributed under the terms of the Creative Commons Attribution Noncommercial License which permits any noncommercial use, distribution, and reproduction in any medium, provided the original author(s) and source are credited. 